\title{
Informal Text Analytics at the Interface of Theoretical Research and Education
}

\author{
Galina Sorina \\ Lomonosov Moscow State University, Leninskiye Gory Street, 1, 119991 Moscow, Russia
}

\begin{abstract}
This article consists of a theoretical and a practical part. The theoretical part focuses on the ideas of informal text analytics (ITA) and the methodology for expert text analysis (META). I examine these ideas at the interface of theoretical research and education. I show that Aristotle's works on logic transcend formal analytics - i.e. logic - to enter the realm of informal analytics. I prove this hypothesis through exploring Aristotle's analysis of question and question/answer procedures (QAP). I emphasise that, when discussing the problem of formulating questions, Aristotle suggests that not only the formal procedures of proof and argumentation but also the characteristics of persons posing questions should be taken into account. The latter builds a bridge between Aristotle's vision and informal text analytics. The practical part comprises the syllabus that I prepared for a relevant course. The syllabus outlines the ways to wed both avenues of analytics.
\end{abstract}

Keywords: philosophy, methodology, logic, informal text analysis, methodology for expert text analysis, Aristotle.

\section{Introduction}

Since the very beginning, research and education have strongly affected each other. However, the public consciousness often treats research and education as independent phenomena. I would like to prove that this is not completely correct and to discuss the cases of methodologically intensive research and researchintensive education [1].

If researchers are interested in teaching, their findings always find a way into their academic routines. Vice versa, teaching encourages professors to undertake research.

Research and education are intertwined with each other. There are numerous cases proving this point.

- One of the most remarkable cases is the discovery of the periodic table by Mendeleev. It does not matter whether Mendeleev first saw his table when he was asleep or awake. According to historians of science, one of the problems that occupied Mendeleev's mind was a possible arrangement of chemical elements to be used as a teaching aid at Saint Petersburg Institute of Technology.

- Speech act theory, which hails from John L Austin's ideas, emerged when he was preparing a course in logic for students of law. It turned out that the classical theory of propositions was not applicable to legal procedures.

- Hegel's philosophy of law is, in effect, a course of lectures on Roman law.

- Kant's works on logic, as Norbert Hinske shows, do not only present logical ideas but also open up a glimpse of the pedagogical origins of Kant's philosophy [2]. Independently from Hinske, in a work co-authored with Prof I N Griftsova, I analyse the same set of problems and prove that the university course that Kant had been teaching for over 40 years affected the philosopher's concept [3].
- The tenets of informal logic were first formulated as syllabi [1].

- Finally, the very origins of philosophical culture lie in education. Aristotle's texts that are not presented in a form of a dialogue - the only texts that survive to this day - include lectures that he delivered in the Lyceum, the cradle of the Peripatetic School.

The list can go on. However, all the cases that can be used to extend it will relate to either the formal or the informal aspect of analytics. Moreover, they will become intertwined within the activities of subjects engaged in an analytical study.

\subsection{Problem Statement. The Aristotelean Origin of Ana- lytics}

Of course, analytics is practice-oriented. When trying to give analytics a clear and consistent definition, one will be faced with a multitude of characteristics and definitions. For instance, an analytical dictionary for managers who solve challenging analytical problems offers several dozen definitions of the term. These definitions are analysed within different texts, including English, German, and Chinese dictionaries. The authors show that there are different approaches to defining analytics and stress that there is no single definition [4].

However, the conceptual core of the notion of analytics is closely connected with the notion of analysis, the latter being easier to define. The idea of analysis encompasses the procedures of the mental division of the objects studied. This is done through identifying relevant attributes, properties, and relationships. In the context of formal logic, the problems of analysis are inseparable from the identification of the logical form of reasoning and a study into the features of concepts, propositions, and inferences.

Although it seems impossible to give a consistent definition of the concept of 'analytics', which ensues from the concept of analysis, one can describe the historical origins of the former concept. It 
safe to say that systematic analytics in the form of an analytical activity dates back to Aristotle. Aristotle's logic is presented in a series of works, the most prominent ones being the Analytics. That is why analytics was understood as an activity closely connected with logic - i.e. as a strict and consistent system. For instance, Schopenhauer identified logic with analytics. He formulated this approach in his work Eristic Dialectic: The Art of Winning an Argument, where he equated analytics with logic: '...his Logic proper, or Analytic' [5].

Aristotle's analytics is perceived as a tool of demonstrative understanding, as formal analytics, and as a formal analytic activity. However, elements of what can be interpreted as informal analytics are present in Aristotle's works. Whereas formal analytics does not take into account the characteristics of the cognising subjects, informal analytics is all about the features of the cognising and acting subjects. I believe that Aristotle embarks on an analysis of the capacities of subjects when he discusses the problems of proof and argumentation and, particularly, the role of questions in them $\mathrm{He}$ addresses these issues in a number of works - On Interpretation, the Analytics, the Topics, and On Sophistical Refutations. In the Topics, Aristotle warns against arguing and 'practising upon the man in the street; for there are some people with whom any argument is bound to degenerate' [6, 164b 10-15]. He expresses a similar thought in the Posterior Analytics when considering the use of questions in demonstration.

For Aristotle, questions are neither strictly organised nor formalised but they have to be taken into account in demonstration and argumentation. Although not strict, when used in research, such questions lead to 'appropriate deductions'. Questions entail and shape demonstration. In $\$ 12$ of Book I of the Posterior Analytics, Aristotle writes: 'there are propositions in each science on which the deductions in each depend, then there will be a sort of scientific question from which the deduction appropriate to each science comes about' [6,77a37-77b2]. He pays special attention to the problem of what today is called professionalism, on the one hand, and disciplinary matrix, on the other. According to Aristotle, to formulate a question, one should take into account to which scientific discipline it relates. 'It is clear, therefore, that not every question will be geometrical (or medical-and similarly in the other cases too), but only those from which either there is proved one of the things about which geometry is concerned, or something which is proved from the same things as geometry, such as optical matters. And similarly in the other cases too. And for those one should indeed supply an argument from the principles and conclusions of geometry; but for the principles, the geometer as geometer should not supply an argument; and similarly for the other sciences too' $[6,77 \mathrm{a} 40-77 \mathrm{~b} 5]$. Aristotle emphasises the role that the questioning subject plays in providing scientific proof, on the one hand, and the need to distinguish between sciences. The subject - 'each scientist' - should avoid questions from a random field. Scientists and scholars have to take into account differences between disciplines. Aristotle speaks of the problem of specialisation and the need to increase the professionalism of research subjects. 'We should not, therefore, ask each scientist every question, nor should he answer everything he is asked about anything, but only those determined by the scope of this science. If one argues in this way with a geometer as geometer it is evident that one will do so correctly if one proves something from these things; but otherwise, not correctly. And it is clear that one does not refute the geometer either, except incidentally' [6, 77b5-13]. Here, Aristotle insists on a strict disciplinary division of science. He writes, 'so that one should not argue about geometry among nongeometers - for the man who argues badly will escape notice. And the same goes for the other sciences too' $[6,77 b 14-16]$. He emphasises that geometry should not discuss problems pertaining to music. For Aristotle, the 'non-geometrical' has two meanings. This is everything that does not relate to geometry, on the one hand, and an erroneous interpretation of something as a matter of geometry, on the other. He calls it 'ignorance', which is the opposite of science. Aristotle constantly stresses that scientific knowledge is discipline-specific and he distinguishes between the 'fact' and the 'reason why'. Aristotle traces the latter distinction across difference sciences. 'For here it is for the empirical scientists to know the fact and for the mathematical to know the reason why' $[6,79 \mathrm{a} 2-4]$. At the same time, Aristotle admits that different sciences can deal with related problems. These sciences 'bear almost the same name - e.g. mathematical and nautical astronomy, and mathematical and acoustical harmonics' [6, 79a1-2].

Such dual problems and the particularities of scientific questioning prevent from a formal establishment of the idea of professionalism in research and education. I believe that, in this context, one can speak of IAT elements in Aristotle. These elements emerge in the analysis of the development of science. In such an analysis, the empirical and theoretical levels become closely intertwined. Aristotle warns against non-professionalism in questioning and stresses that not only the form but also the content is relevant. He formulates a series of rules of valid argumentation. First of all, one needs to be familiar with many definitions. However, the psychological makeup of the subject is equally important. The subject has to have 'the power of discerning', to 'choose the true', and to 'shun the false'. Aristotle stresses this in the eighth book of the Topics, where he revisits the role of the subject, who should 'know thoroughly arguments', remember the premises and the arguments of the opponent, and keep in mind that everyone is trained in their thing [6, 163b17-164a15]. In this chapter, Aristotle returns to the analysis of procedures relating to the problems of questioning. He writes that, in a discussion, it is important to understand 'whether some one put his question properly or improperly' $[6,164 \mathrm{a} 18]$. The same problem is addressed in On Sophistical Refutations, where Aristotle analyses 'how to question or arrange the questioning as a whole, and the problems concerning the answers and solutions to be used against the deductions of the questioner' $[6,183 \mathrm{~b} 5-10]$.

\subsection{Purpose of the Study}

As I said above, the question/answer procedure (QAP) and syllogistics are closely connected. When formulating questions, it is important to identify necessary propositions. 'By necessary propositions are meant those through which the deduction is constructed' [6, 155b19-20]. Questions should focus on 'the point which one most wishes to have conceded' $[6,156 \mathrm{~b} 30]$. I believe that, alongside what we might call today the scope of a profession and the psychological makeup of a professional, Aristotle discusses the structural characteristics of questions. In fact, he analyses the characteristics of the explicit premises of questions and the ability to use them properly. The explicit premises of questions provide the initial information that questioners use to form the foundation of their questions and that makes it possible to understand the level of questioners' professionalism. In examining a subject engaged in a discussion, one starts to understand that analysis cannot be reduced to mere formal text analytics (FTA), to factors independent from the characteristics of the cognising subject. Through addressing the subject and their characteristics, one creates grounds for the inclusion of the ITA tool into analytics.

Thus, Aristotle is, on the one hand, a thinker who shaped the structure of theoretical scientific knowledge. On the other hand, Aristotle's works survive to this day in the form of 'lecture notes' - texts that had been delivered to the students of the Peripatetic School. I believe that these texts are an embodiment of the link between research and pedagogy. It seems that these texts contain the idea of a connection between formal and informal text analytics. Aristotle's texts on logic have an informal analytics facet to them. This becomes evident if one examines Aristotle's analysis of questions.

The emergence of the art of argumentation and demonstration is closely linked to the development of interrogative reasoning. The structural features of questions betray the cognitive and psychological characteristics of the subjects who formulate these ques- 
tions. The external independence of statements presented as questions contributes to the creation of different types of communicative ties and to the development of research and education - this is exactly the point of the 'lecture's notes'. It is important to remember that questions determine the scope of the search for possible answers, i.e. contribute to the development of respective disciplines and education. I would like to stress that, in effect, the structure of a question - manifested, for instance, in a question's explicit premise - predetermines the possible answers and delineate a semantic field for the search for possible answers and thus shapes the characteristics of ITA.

I believe that an analysis of the questioning stance in ancient philosophical thought is absolutely necessary for understanding the emergence of argumentation and demonstration processes - particularly ITA - and the development of philosophy in general. Questions help to elucidate main theses and arguments, to eliminate errors in reasoning, and to control the quality of argumentation. Questions depend on the cognitive and psychological makeups of the subjects who formulate them. This is a crucial characteristic of ITA in both research and training.

Later in history, formal logic would not consider questions. From the perspective of formal logic, interrogative sentences are neither true nor false. Interrogative sentences give a clear indication of the uncertainty of knowledge. As mentioned above, the need to eliminate this uncertainty is key to the psychological state of the questioner. Questions were not only removed from the scope of formal logic, they ceased to be an object of scientific analysis. The removal of questions from the scope of logic became a paradigm enshrined in school textbooks. A typical example is a textbook written in the early $20^{\text {th }}$ century by I D Gorodetsky. He wrote: 'Logic deals with neither interrogatory (where were you?) sentences nor imperative ones (give me a pen). The thoughts expressed in such sentences are not propositions and they cannot be considered knowledge (italics mine - G S) that always states or denies something and never questions or urges or does anything else of this uncertain kind' [7, p. 16].

\section{Methods}

However, an examination of question/answer procedures and their comprehensive interpretation allows one to name QAPs a necessary instrument of research and education. This tool is of crucial importance for understanding and explanation, interpretation and evaluation, analysis and synthesis. It proves the need for investigating not only formal but also informal text analytics.

\section{Results}

\subsection{The Inseparability of the Subject from Intellectual Activities, Namely, Research and Education}

I believe that the above cases prove that the link between research and education is universal. The connection between research and teaching can be traced across different forms of historical reconstructions. Another way to prove this link is to identify the contribution of concrete researchers and teachers to the development of concrete fields of knowledge and education. It seems that today the importance of this connection is increasing not only at the level of differences between disciplines - which was noticed by Aristotle - but also in the framework of current trends in interdisciplinary and transdisciplinary research. In the circumvolution of ideas and problems, one can see that, as a trend, interdisciplinary studies preserve the belief that science develops independently from the characteristics of the cognising subject. At the same time, the development of transdisciplinary studies and their theoretical reworking have an immediate bearing on the idea of the subject's inclusion into research and education and of the dependence of findings on the actions of the subject.
It seems important to stress that the very phenomenon of transdisciplinary studies has developed hand in hand with the educational environment and the current forms of knowledge generation. In both cases, the subject of research and education is inseparable from the content of either science or training. Informal text analytics suggests taking into account relevant feedback, the characteristics of the subject, and how associative connections relating to the text analysed are established. I will explicate this idea in the practical part of the article in the fourth column of an analytical report produced in the framework of the META.

As never before, the identification of the role of the subject in research and education is affected by the global problems of our times. The context of the search for a relevant connection proves to be informal. Therefore, this connection falls within the realm of informal text analytics. An example of such an approach employed to solve analytical problems is the methodology of expert text analysis (META; Prof. Sorina obtained a patent and an intellectual property certificate N AAAA- $Г 17-617060110019-6$ of $01 / 06 / 2017$ for the methodology for expert text analysis (META)), which was first developed for the purposes of teaching.

Later, it turned out that the general principles of the META are applicable to other activities - including research - where work with texts plays a crucial role. The META suggests a new informal approach to the organisation of an educational space. In the context of this approach, the subjects of an educational space - in this case, students and teachers - are linked by horizontal relations of collaboration rather than by vertical ones that are immanent in the classical approach.

The idea of creating an informal context for the organisation of an educational space is formulated in a recent report to the Club of Rome. The authors of the document believe that the development of critical thinking, the ability to solve problems, and decisionmaking skills in students is a key objective of education. The report stresses the need for a transition to a new paradigm for education. 'Future education is active and collaborative. Research confirms that comprehension is lowest for passive pedagogical methods such as reading or listening to a lecture and that learning is at a maximum when it is cooperative, for example, during a discussion, group project or combined study' [8, p. 197]. At the same time, the document pays attention to the value-related and ethical problems of the organisation of an educational space.

\subsection{The Key Principles of the META-Based Organisa- tion of an Education Space}

A case of the organisation of an educational space in line with the principle of the inseparability of the subject from intellectual activities, as well as a case of informal text analytics combined with formal text analytics, is the methodology of expert text analysis (META). I have worked on the methodology for over twenty years. Therefore, I formulated my ideas much earlier than the authors of the report to the Club of Rome did.

The META context is characterised by the following.

1) There are clearly defined scopes of responsibility for the results of the collaboration. In particular, they are described in the organisational and ethical guidelines.

2) Students are responsible for each other's work and help each other to attain the desired results. It turns out that the process of education cannot be reduced to responsibility towards teachers (giving an answer - not giving an answer) and parents (passing an exam - failing an exam). The scope of responsibility is defined by the fact that experts can never perform if the group is not ready.

3) The spatial organisation of the lecture room changes. The experts sit at the teacher's table and the teacher takes one of the rear seats. The teacher is in control of the discussion and they do not cede leadership to the expert group. This is ensured by questions asked by the chief expert (the teacher) and the 'panel' discussions of the most difficult problems - when 
the teacher returns to the teacher's table thus adjusting the group's dynamics.

4) A new spatial-organisational component is introduced. Students are given triangle desk signs with their first and last names on them. Thus, the teacher can always call a student by name. It is impossible to remember all the names at once. The desk signs contribute to a feeling of trust.

5) Each class is concluded with a reflexive analysis. The experts analyse the work of the group and the group the work of the experts. A reflexive analysis is made possible by the ethical and organisational META guidelines.

It seems important to stress that the META has established itself as a methodological framework used by undergraduate and graduate students in their research efforts. In particular, it is employed in works on decision-making theories, problems of leadership, expertise in the humanities, and identity problems.

Another important factor in the circumvolution of research and education is that our current research is of interest to our students. This is another case of the circumvolution of research and education.

From Antiquity to these days, a characteristic feature of the education system has been work with written texts. Whereas the classical educational system worked with texts printed on paper, the educational system of today is embracing the analysis of digital texts. Texts - primarily, written ones - create conditions for, and make possible, the professional organisation of the teaching process. Historically, written texts lay at heart of interactions and mutual influences between education and science.

The results of these interactions did not become evident at once. Reliable and consistent research results were being published one by one in open-access media. Of course, this did not happen in the case of classified studies. Later, research results were entering textbooks, thus becoming an element of the educational system. Using the results presented in different of written texts, the educational system was immersing school and university students in a range of research contexts. These contexts were shaping people oriented towards scientific cognition and professional scientific work. Then, it was history repeating.

Until the late 1990s, the principal sources of information in the educational process were texts printed on paper. If a special professional interest arose, textbooks were supplemented by research articles and monographs. Such a circumvolution of people and ideas has been characteristic of both research and education throughout their history and the history of their mutual influence. However, a methodological framework for dealing with texts in the educational processes and for text analytics as a special theoretical and practical area has been rarely addressed in research. The methodology for working with texts in the educational process is not a common object of systematic studies. Among the few works focusing on these issues are those of S I Povarnin. One of them - The Art of Dispute. On the Theory and Practice of Holding an Argument - appeared in Petrograd in 1923. His booklet How to Read Books was published in the same place in 1924. Although remaining relevant to an extent, these works obviously do not address today's educational process problems. Moreover, Povarin did not consider the problems of education per se and he could not foresee the powers of the information technology. The META is an attempt to take into account these powers.

In research, informal text analytics turns into a means to provide feedback on the subjects who read and analyse a text through the prism of their occupation, experience, and cognitive preferences.

\subsection{Decision-Making Course Syllabus}

Ancient intellectual practices can be considered as a precursor of the contemporary theory of decision-making [9]. The below syllabus of a decision-making course uses the meta to bring together research and training routines and takes into account the particu- larities of ITA. These particularities are considered in column 4 of the analytical report (see the table below).

Discipline: Introduction to Decision-Making

Compiled by G V Sorina

1. Goals

This course is part of the Methodology for Expert Text Analysis, which was developed by Prof Sorina. The course aims to acquaint students with the methodological framework of decision-making and help them to develop competencies necessary for handling practical situations.

The other goals include:

- familiarising students with the key concepts and methods of decision-making;

- developing skills of managing the intellectual activity when:

- making different types of decisions, including those in PR and GR;

- justifying and defending one's decisions and ideas.

- To reach these goals, the following objectives should be attained:

- developing key competencies in the methodology of decision-making;

- developing skills of using the obtained results in practice;

- developing the ability to a see a union in differences between decisions of various types and levels;

- involving students into practical work, in particular, through developing skills in preparing analytical reports on the "Introduction to decision-making" course;

- developing a critical style of thinking in the conditions of rapid changes in modern innovative societies oriented to building the knowledge economy;

- stimulating the individual search for interdependencies between the theory and practice of decision-making in PR and GR (through analytical report preparation).

2. The role of the discipline in the major higher educational programme. The discipline "Introduction to decision-making" is closely related to the other disciplines of the programme for training specialists in advertising and PR. Advertising in a communicative process, managing a PR agency, managing mass media relations, overcoming conflicts and negotiations, marketing research, managing a modern press service, managing political communications, etc. require consecutive decision-making and implementation thereof. The discipline presents the meta-level of the theory of decision-making (TDM).

Moreover, the mastering the discipline is necessary for developing universal competences of an MSU graduate, including:

taking responsibility for the results of one's professional and research activities;

being capable of presenting one's perspective and effectively implementing the decisions reached;

showing skills of an independent and methodologically adequate text analysis;

showing skills in holding a dialogue, presenting one's position, and persuading the opponent;

being capable of searching for and analysing information necessary for decision-making;

being capable of individual study and performing innovative research and educational activities.

3. The total load of the discipline is 2 ECTS-credits (32-36 academic hours).

4. The structure and content of the discipline:

a) Elements (Table 1) 
Table 1:. The structure of the Discipline.

\begin{tabular}{|c|c|c|c|c|c|}
\hline No & Discipline element & Lectures & Recitations & $\begin{array}{l}\text { Individual } \\
\text { study }\end{array}$ & Total \\
\hline 1 & $\begin{array}{l}\text { Discipline concept. Features of the expert group methodology. Critical thinking as a } \\
\text { necessary condition for the decision-making process. Practical orientation of critical thinking. } \\
\text { History of decision-making theory. Features of decision-making in different social practices. }\end{array}$ & 2 & 0 & 2 & 4 \\
\hline 2 & $\begin{array}{l}\text { Intellectual tools for decision-making. A general characteristic of intellectual tools. The } \\
\text { concept as an intellectual tool. Operating with concepts as a necessary element of solving } \\
\text { intellectual problems. Judgment as an intellectual tool. Distinctive features of the concept of } \\
\text { "judgement." Judgement as a form of decision. Key objectives of judgements in the process } \\
\text { of decision-making. Analytic and synthetic judgements. The role of "suspended judgement" } \\
\text { in the process of decision-making. The stages of decision-making as stages of judgement } \\
\text { formation. Links between a judgement and a question. Questions as an intellectual tool. }\end{array}$ & 2 & 0 & 2 & 4 \\
\hline 3 & $\begin{array}{l}\text { Question-answer procedure in the decision-making process. Question-answer procedures } \\
\text { (QAP) as a crucial tool for creative thinking and innovative decisions, in particular, in PR } \\
\text { and GR. Search for creative decisions as a key problem of modern PR. Key features of the } \\
\text { problem. The efficiency of the ancient questioning schemes in the modern theory and } \\
\text { practice of decision-making. The methodology of managing thought through the QAP } \\
\text { system. Types and levels of questioning. Methods of questioning in different management } \\
\text { styles. The place of QAP in the process of decision preparation and making. The structure } \\
\text { and functioning of questions. A question as an indicator of the status of the inquirer and their } \\
\text { cognitive competence. QAP classification. }\end{array}$ & 3 & 0 & 3 & 6 \\
\hline 4 & A tutorial session on question-answer procedures in decision-making theory. & 1 & 0 & 1 & 2 \\
\hline 5 & $\begin{array}{l}\text { A conceptual framework of the decision-making process. A general framework of operating } \\
\text { with concepts in different areas of human activities. A concept as a form of presenting } \\
\text { different areas of human activities. Professional features of presenting conceptual strategies. } \\
\text { Problems of defining abstract objects. The abstract nature of the concepts of "decision" and } \\
\text { "decision-making." The need for rational criticism of concept systems. Dependence between } \\
\text { the image of the world and concept strategies. }\end{array}$ & 2 & 0 & 2 & 4 \\
\hline 6 & Tutorial session on the Conceptual framework of the decision-making process. & 1 & 0 & 1 & 2 \\
\hline 7 & $\begin{array}{l}\text { Stable elements of the decision-making process. The military origins of the schematic nature } \\
\text { of decision-making process. Features of structuring the decision- making process according } \\
\text { to H. Simon and H. Mintzberg. Obtaining information and the ways to interpret it in the } \\
\text { course of decision-making. Different methods of search for decisions. The role of collecting, } \\
\text { identifying, and exploring information in the process of decision-making. The problem of } \\
\text { interpretation in the process of decision-making. Understanding the problem as a crucial step } \\
\text { in the process of decision-making. The role of reflexion and critical thinking in } \\
\text { understanding the problem. Formulating the purposes of the decision-making process. }\end{array}$ & 3 & 0 & 3 & 6 \\
\hline \multirow[t]{2}{*}{9} & $\begin{array}{l}\text { Levels of decision-making. The basis of the classification of decision-making levels. } \\
\text { Everyday decision-making. Professional decision-making. Classification of decision-making } \\
\text { levels by analogy with the military practice. Similarities between military strategic, political } \\
\text { strategic, and organisational strategic decisions. }\end{array}$ & 2 & 0 & 2 & 4 \\
\hline & Total & 18 & 0 & 18 & 36 \\
\hline
\end{tabular}

b) Contents (including all didactic units of the course).

This course includes an analysis of different methodological features of decision-making in different areas of human activity. This suggests not only analysing different managerial issues traditionally associated with the problems of decision-making, but also philosophical texts containing theoretical examples of decisionmaking. Overall, it is the philosophical perspective that offers examples of decision-making as to choosing the conceptual framework, abstractions, and idealisation used in the process of decision-making.

At the current stage of the society's development, studies into the problems of decision-making and the identification of the features of methodological frameworks for, and the language of, decisionmaking are particularly relevant to the problems of the development of civil society, on the one hand, and knowledge society, on the other.

This course stresses the idea that there are no strict universal algorithms of decision-making relevant to all areas of human activities, however, there are

- general mechanisms of intellectual activity that have a universal nature and determine the process of decisionmaking;

- models and methods of decision-making used in different areas of professional and everyday human activities.
All these ideas are revisited in each topic presented in section a) elements of the discipline paragraph 4 "the structure and content of the discipline."

\section{Educational technology.}

Educational technologies employed in organising the discipline "Introduction to decision-making" are determined by the methodology for expert text analysis (META). The organisation of classes in the framework of this methodology emphasises the idea that:

- in both practical and theoretical activities, a human being acts as an intellectual and sentient being - they operate with concepts and judgements, make conclusions, set questions, and get answers. Refined examples of this activity will be studied in the course;

- practical analysis of texts on decision-making will prove useful for certain activities, for informal text analytics (ITA);

- $\quad$ work in the framework of the methodology for expert text analysis (META) expert group is teamwork, whose results depend on the performance of both the whole team (class, study group) and a selected subgroup (expert group). The experts cannot work efficiently if the team is not ready;

- this methodology meets the requirements of the modern information and cognitive society, which places special em- 
phasis on the actions of the agent, expert work, and expert examination.

A qualified expert examination (in all its forms) is possible only under the condition of an adequate level of professionalism. At the same time, any expert examination covers an analysis of different texts (philosophical, legal, financial, economic, and political documents, different projects, programmes, contracts, PR and GR, management, strategic management documents, etc.). Regardless of the text content or specialisation, the work with any text is based on the same humanities technology. This technology is the basis of the individual study (IS) of students and is used in the course of tutorial sessions and in-class work.

The work of expert groups helps students to develop:

- the ability to manage their intellectual activity and critical thinking, which is manifested not only in the framework of the discipline but also in professional activities;

- the propensity to work, firstly, individually, and, secondly, in a team;

- the ability to perform expert work aimed at preparing and implementing decisions.

This methodology contributes to students' interest in humanities technologies and decision-making theory.

The methodology is based on a system of organisational and ethical guidelines (organisational guidelines cannot function without ethical guidelines), which are presented in the introductory lecture and developed in the framework of tutorial sessions and individual study.

Ethical guidelines:

- During the course, the class acts as a single agent. If mistakes are made when discussing the problems in question, they are interpreted as mistakes of a collective agent present in the class.

- If a member of the class makes a mistake and another student corrects it, the latter does not do a 'bad favour' but contributes to the development of the group.

- An analysis of each other's work contributes to the development of both the collective agent and each individual.

- Critical judgements should be tolerant and expressed in the form of a critical reflection and dialogue.

- If the expert cannot visit a tutorial session, they have to delegate their assignment to another group member.

- Organisational guidelines:

- Expert groups are set up by students themselves.
- In case no group member wants to act as an expert, experts are appointed by the lecturer.

- An expert group consists of at least two people (otherwise, it is not a group) and maximum four people (if there are more than four experts, the group proves to be incapable of self-organisation and self-management).

- The structure of the task (for instance, the analysis of a certain text on decision-making in PR and GR) is the same for the group and experts; of course, expert students traditionally prepare more material on the topic.

- Before a tutorial session, experts gather together and discuss the strategy and tactics of their conduct during the practical session (the order of speakers asking questions and commenting on answers)

- A tutorial session takes the form of a training game, where everyone including the key expert (lecturer) has a right to ask questions. The questions determine the rhythm and direction of the work. This is not a coincidence for Socrates ascertained the fact that the question guides the audience.

- The expert has a right to introduce the topic within a 3-5 minute time limit. Then they formulate questions for the group based on a certain text. The questions a prepared at home in writing. If the expert does not accept the answer given by the group, they should not correct the person who gave the answer right away. The expert provides a summary after several other answers are given and the group is ready to summarise the results.

- A general summary is provided at the end of the tutorial session: the group evaluates the experts and vice versa. This analysis becomes possible based on the above ethical rules. Criticism is considered as a tool for developing the intellectual abilities of all agents working in the group - both individual (certain people participating in the tutorial session) and collective (expert subgroups and the team in general) ones.

- Concrete texts corresponding to the course topics are discussed at tutorial sessions.

- Students should have a special folder for collecting "description papers" for each text, which will compile the analytics report on the course "Introduction to Decision-making" at the end of the semester.

Analytics reports are prepared on A4 papers. Each page is divided into the following columns (Table 2):

Table 2:. Report table.

List of key concepts and their major characteristics

Questions about the
text ments
Possible associations and analogies from the professional field of the author of the report
In effect, only the content of the first column will be the same across the reports of all students. Other sections of analytical reports will reflect the individuality of the authors of reports. Lectures and tutorial sessions do not repeat but rather complement each other. Texts for analysis change, but the text selection parameters are determined by the topic of the course.

In the framework of the discipline, the methodology for expert text analysis (META) is practically oriented, since students develop not only necessary skills in the theory and methodology of decision-making but also analytical skills in the methodology for expert text analysis (META). These skills are later used in analysing professional texts the levels of both formal text analysis (FTA) and informal text analysis (ITA).

The methodology for expert text analysis is based on the team principle and personal responsibility of each group member for the results of understanding and presenting their work.

The results of individual in and out of class studies aimed at mastering the material are presented in analytical reports and thus are subject to control.

\section{Conclusions}

This is the first article to describe an approach to the study of Aristotle's analytics in view of the distinction between the formal and informal analytics of texts used in research and training. The two types of analytics are identified using Aristotle's approach to the analysis of the role of questions in the structure of demonstration and argumentation within a certain professional field. I show that this approach remains relevant to this day. An important feature of today's world is the increasing importance of the growing professionalisation of research, teaching, and any other social activity. The accelerated development of different branches of production, including the 'production' of professionals within a multi-tire educational system, lends urgency to the question about the universal principles of professional training, the place of professionals in today's social structures and processes. This can only emphasise the importance of the disciplinary division of research and education, as well as of interdisciplinary and transdisciplinary ties in research and training. 


\section{Acknowledgements}

The study is supported by a grant from the Russian Foundation for Basic Research within the 'Informal Text Analytics: A Philosophical and Methodological Approach' project (N 17-03-00772).

\section{References}

[1] I.N. Griftsova, Logika kak teoreticheskaya i prakticheskaya distsiplina. $\mathrm{K}$ voprosu o sootnoshenii formalnoy i neformalnoy logiki. Monografiya [Logic as a Theoretical and Practical Discipline. On the Correlation between Formal and Informal Logics. A Monograph], Editorial URSS, Moscow, 1998.

[2] N. Hinske, Zwischen Aufklärung und Venunftkritik: Studien zum Kantschen Logikcorpus, Frommann-Holzboog, 1998.

[3] G.V. Sorina, I.N. Griftsova, Kant's Philosophy of Education: A Dialogue through Centuries, Espacios 38(40) (2017) 42-51.

[4] Yu.N. Koptev (ed.), Analiticheskiy slovar [Analytical dictionary], Moscow, 2015.

[5] Schopenhauer, The Essays of Arthur Schopenhauer - The Art of Controversy, Full Moon Publications, 2016.

[6] Aristotle, Complete Works, Vol. 1, 2, Princeton University Press, Princeton, 2014.

[7] I.D. Gorodetsky, Logika. Uchebnik dlya gimnazii i samooobrsazovaniya [Logic. A textbook for Schools and Lifelong Learning], Energiya, 1916.

[8] E.U. von Weizsäcker, A. Wijkman, Come On! Capitalism, Shorttermism, Population and the Destruction of the Planet, Springer, 2018.

[9] V. Diev, G. Sorina, I. Griftsova, Document Ancient Intellectual Practices as Forerunners to the Modern Theory of Decision-making, Shole, Philosophical Antiquity Studies and the Classical Tradition 11(2) (2017) 515-523. 